\title{
A Corpus Based Study: Analysis of the Positive Reviews of Amazon.com Users
}

\author{
Lokman Altun* \\ Department of Foreign Language Education, National Defense University, Turkey \\ Corresponding Author: Lokman Altun, E-mail: 1kmnaltn58@gmail.com
}

\section{ARTICLE INFO}

Article history

Received: October 09, 2018

Accepted: December 05, 2018

Published: February 28, 2019

Volume: 10 Issue: 1

Advance access: January 2019

Conflicts of interest: None

Funding: None

\section{Key words:}

Consumer Reviews,

Corpus-based Study,

Real Life English,

English in Use,

Comment Analysis

\begin{abstract}
This study aims to investigate online consumer reviews on Amazon.com. Thanks to this study, learners can make use of this study when they prefer a corpus based learning strategy especially for the product reviewers. This study includes two aspects of review structure. The frequency of adverbs, adjectives and verbs that are mostly used together are main focus in this study. Adjectives and adverbs that are used more and which collocations are used more with that adjective and adverbs were examined. In addition, it was examined which verbs are used mostly when people try to show their phrases. This study is quantitative study with survey design. In order to collect data, different Apple products were analyzed such as iPhone 7, Apple Watch 1 and Apple Watch Series 3, Apple Airpods. An analysis of 1,587 reviews which were 4 or 5 stars from Amazon. com across four products pointed out that online consumer reviews have a very effective role in terms of the sales of products. To assure the validity and reliability of the process, a teacher who has a very good knowledge about linguistic checked reviews and came to an agreement with the researcher. Descriptive analysis was used in this study by calculating frequency of adverbs, adjectives and verbs. It was found out that consumers generally prefer specific verbs, adverbs and adjectives in a specific context. This study may help to understand the linguistic background of consumers. As a result of the study, it was seen that some adjectives, adverbs and verbs were mostly chosen deliberately by the users. This study also resulted that these words have some specific collocation words. These collocation words were used by the users both before and after that adjective, adverb and verb. As an implication for this study, new writing topics that this study has suggested can be integrated to the curriculum. These topics can be seen as a new way for writing lessons.
\end{abstract}

\section{INTRODUCTION}

Online shopping is getting more and more common. There are lots of websites that provide consumers to buy something without going anywhere. Consumers decide whether to buy or not to buy that product by examining reviews. Thanks to reviews, the consumer can overcome the problem as the consumer does not have a chance to examine or see the product. Consumer reviews are more important because people firstly look at reviews on websites. As people rely on the comments of the consumer, comments have a big role in online shopping. According to comments, the number of sales can increase or decrease. According to Ba and Pavlou (2002) and Pavlou and Gefen (2004), positive feedbacks can affect buyer trust. Reviews help consumers to decide easily. Online shopping websites ask for the opinion of the consumers. With the help of websites, consumers can evaluate reviews. Another issue is "measurability (Lee, Park \& Han, 2007). In online websites, consumers can easily understand the quality and quantity of products because all of the reviews are in written context (Lee, Park \& Han, 2007). Consumers can also categorize reviews in terms of positive and negative reviews. In websites, there are positive and negative comments. In the website, when you examine reviews, a consumer can select any reviews and consumer can see the most popular and the worst review about that product. Even websites such as Amazon.com enable consumers to see previous reviews about products. A consumer can easily examine reviews even years later. According to Mudambi and Schuff (2010), consumers visit websites much more and the spent time on websites increases with the help of reviews.

In terms of online corpus studies, a new corpus study was conducted for online writing. This study focused on positive reviews on Amazon.com and aims to see the adverbs and adjectives that were used most and then tried to find words which were used with these adjectives and adverbs with the help of concordancer. Finally, the most used verbs were identified by examining five different products on Amazon. com. This information was collected in order to create a new corpus at linguistic field. However, after being considered these ideas, the researcher realized that there was not any study which were conducted before in online corpus context but linguists really need a new corpus for online writings because the importance of technology is getting more and more common. Linguists should catch the era but there was 
a huge gap at the context of online corpus. The need of a new online corpus study was inevitable. This study will fill this gap at linguistic field. That's why the researcher formed the research question below to investigate the consumer reviews linguistically.

1) Which adjectives do people use to express their praises most in online context?

2) Which adverbs do people use to express their praises most in online context?

3) Which verbs do people use to express their praises most in online context?

\section{LITERATURE REVIEW}

\section{Online Consumer Reviews}

Thanks to online consumer reviews, people can get information and see advice from the customer perspective (Lee, Park \& Han, 2007). According to Coombs and Holladay (2002), the less reputable store receives positive ratings but two reviews are different in terms of their presences. In a survey of 5,500 Web consumers conducted by BizRate, $44 \%$ of respondents said they had got help from sites before buying a product and 59\% considered reviews of consumers more effectively than expert reviews (Piller, 1999: p.3). Chevalier and Mayzlin (2006) and Dellarocas (2007) claim that negative reviews decrease sales while positive consumer reviews increase sales. People also spent their times on these websites to read or write reviews. Reviews can be in different lengths, but the very active members of consumer communities spend about an hour in writing a review (Utz, 2009). With the technological development, internet has been an important part of our lives. Avery, Resnick and Zeckhauser (1999) claim that with the development of the Internet, word-of-mouth has started being common in small societies and communities which is freely ready for use through large-scale consumer networks. With the importance of the Internet, a new term was started to be used in online reviews. Electronic word-of-mouth is a term which is used for online reviews nowadays. Word-of-mouth communication has always been considered a powerful influence factor on consumer behavior (Whyte, 1954; Kerkhof \&Van Noort, 2010). Lee, Park and Han (2007) think that WOM (word-of-mouth) communication affects consumer attitudes on a large spectrum of products and services. Different from traditional WOM, WOM on the Internet, which is known as electronic word-of-mouth (eWOM), is perceptible as comments on a product are written and available on the websites (Godes \& Mayzlin, 2004). Mudambi and Schuff (2010:5) define it as "peer-generated product evaluations posted on the company or third-party websites". What consumers pay attention when they buy something is also another issue. Park and Lee (2009) found that consumers take care of reviews in case of experience products than in case of search products. Other researchers have focused on how consumers process the information provided in reviews and searched the role of possible moderators such as involvement, motivation, or product category (Harris \& Gupta, 2008; Park $\&$ Kim, 2008). People generally concentrate on stores, early shipping, careful packaging of fragile products, and good customer service (Utz, Kerkhof \& Bos, 2012). According to Zhu and Zhang (2006), empirical results support the view that online WOM affects consumers' purchasing behavior.

\section{Corpus Based Study}

Corpus based study may be defined as the investigation of collections of texts. These pieces have been collected according to a specific criteria or a context. The knowledge of this academic vocabulary list is important for both reading effectively and writing appropriately in a specific area (Corson, 1997). This academic list will provide linguists or teachers a useful guide to help them decide which vocabulary should be taught firstly (Nation, 2001:258). When the effect of corpus based study on education, knowing specific words in a context is so crucial. Coxhead (2011) who is developer of Academic World List (AWL) said that this list was created to set goals teachers for their students' academic vocabulary learning. Valipouri and Nassaji (2013) described that within English for Academic Purposes (EAP), academic texts were examined so as to find specific and distinctive features of academic lists.

When different study areas were investigated, it was understood that there were different types of corpus. For example, Wang, Liang and Ge (2008) proposed a new corpus for medical aims and created Medical Academic Word List (MAWL). A corpus for applied linguistic was developed by being explored 1.5 million words (Vongpumivitch, Huang \& Chang, 2009). Martinez, Beck and Panza (2009) searched 826,416 words in AWL for agricultural aims and they tried to create a new corpus for agriculture. Li and Qian (2010) examined 6.3 million words for financial aims. At the light of these studies, the necessity of a new corpus for online writing has gained importance. As it is clearly understood that there is no specific corpus for online writing, making a new online corpus will fill the gap. Nevertheless, generalizing these words can be misleading. Since every student has different needs, students should develop their own word lists that can meet their specific needs (Ward, 2009).

\section{METHOD}

This study plans to find out the most common adjectives, adverbs and verbs which were used by the consumer's comments on Amazon.com and also aims to identify which words especially were chosen to use with them. This is a quantitative study with survey design.

\section{Data Collection}

By examining the reviews on Amazon.com about Apple products, data collection was completed. For iPhone 7, Apple Watch 1 and Apple Watch Series 3, Apple Airpods, there were 5312 reviews. After examining reviews, 1,587 reviews were taken into consideration because researcher limited the data by sorting 4 and 5 stars out of five since the study focused on the positive feedback. Studying on 4 or 5 stars reviews also helped researcher in order to create an effective online corpus. 


\section{Data Analysis}

The analysis of reviews was made by using AntConc which is a tool to show the frequency of words in the text. Thanks to AntConc, the most used adverb, and adjectives were found. Then, the researcher started studying on collocation words. With the help of AntConc, it was found which words are used mostly with that adverb or adjective. The most used verbs are also found by using AntConc, researchers pointed out the frequency of words and made a table according to the results in AntConc.

Table 1. The frequency of adjectives and adverbs and collocation of adjectives and adverbs

\begin{tabular}{|c|c|c|c|c|}
\hline Frequency & Part of speech & Words & Collocation (before) & Collocation (After) \\
\hline 687 & adj. & very & Work & good, impressed, light, well \\
\hline 671 & adj. & great & work, really & phone, camera, product \\
\hline 647 & adj. & good & pretty, very, really & looking, audio, enough \\
\hline 575 & adj. & new & brand & color, phone \\
\hline 573 & adv. & really & generally verb "be" & fast, good, great \\
\hline 389 & adj. & nice & very & Feature \\
\hline 384 & adj. & easy & really, very & use, see \\
\hline 377 & adj. & charging & simple, faster & port, case \\
\hline 376 & adj. & different & & modes, band \\
\hline 374 & adj. & long & very, work & battery \\
\hline 373 & adj. & amazing & absolutely, simply & sound, product \\
\hline 372 & adj. & excellent & mostly, such & picture, product \\
\hline 184 & adj. & fast & really, very & And \\
\hline 184 & adj. & big & no & difference \\
\hline 184 & adj. & pretty & seem, look & much, quick, good \\
\hline 183 & adj. & awesome & look & watch, technology \\
\hline 182 & adv. & Finally & & got, has \\
\hline 180 & adj. & looking & good, best & \\
\hline 180 & adv. & truly & generally verb "be" & magical, wireless \\
\hline 179 & adv. & actually & & Think \\
\hline 179 & adv. & definitely & would & recommend, overprice \\
\hline 179 & adj. & last & over & Year \\
\hline 178 & adj. & useful & extremely & and, item \\
\hline 177 & adv. & absolutely & & love, amazing \\
\hline 172 & adv. & quickly & Pretty & \\
\hline 170 & adj. & fine & adapter, audio, work & \\
\hline 169 & adv. & automatically & music, device & pause, \\
\hline 168 & adv. & easily & so, very & possible \\
\hline 167 & adv. & extremely & generally verb "be" & useful \\
\hline 167 & adj. & happy & pretty, very, so & with \\
\hline 165 & adj. & fantastic & generally verb "be" & shape \\
\hline 164 & adj. & comfortable & extremely & to wear \\
\hline 162 & adj. & cool & so, very & Feature \\
\hline 161 & adv. & certainly & generally verb "be" & \\
\hline 161 & adv. & probably & generally verb "be" & work \\
\hline 161 & adv. & slightly & very & better \\
\hline 160 & adj. & impressed & very, so & \\
\hline 159 & adj. & surprised & pleasantly & \\
\hline 153 & $\mathrm{adv}$ & honestly & & \\
\hline
\end{tabular}




\section{RESULTS}

As a result of data collection process, data were analyzed and results were tabled (Tables 1 and 2).

Adj: adjective

Adv: adverb

As people want to rely on consumer's comments on websites, adjectives and adverbs that are used by consumers have a big role in selling rates. According to the table, the most used adjective is "very". People preferred to use "very" with an adjective. Most of the comments include "very good, very impressed". These comments have a good effect on people's ideas. "Great, good, new" are also other adjectives that are used most frequently. The table shows us that people use a noun or adjective before adjectives. People also use adjectives after these adjectives. There are also interesting adjectives that express consumer's praises. "Cool, impressed, comfortable" are just three of them. The meaning of these adjectives is beyond the meanings of great or good. They have much more effective meaning and these adjectives affect people positively when they are examining reviews. For adverbs, consumers generally chose to use adjectives that express sincerity. It is considered that consumers generally use "really" for an adverb. "Really" is the most used adverb. It is used 573 times in comments. Consumers use "really" as they want to show their sincerity. "Truly, definitely, actually" are just three of them. Adverbs also are used with a verb or noun. Consumers wanted to show their satisfaction by using "absolutely amazing, definitely recommend". These are the most used collocations for adverbs. Reviews have a key role in selling. As people know this fact, they always try to use more adjectives and adverbs than in daily lives. People generally use common or effective adjectives and adverbs to convince people. Adjectives or adverbs have the same collocation and people prefer to use these words with definite adverbs or adjectives. To be able to create an online corpus, knowing these keywords are so crucial.

According to findings, consumers use mostly verbs that show their pleasures. "like, love" are two most used verbs in reviews. As our products are technological devices, people usually tend to write about the brand new product after pleasure verbs. They also use purchase frequently. As they watch out the function of the product and its appearance, "work and fit " are used too often. People also preferred to start the sentence by using "I". Sentences are generally impersonal. People generally talked about the advantages and disadvantages of products. As products have more advantages, people recommend the products to us.

\section{DISCUSSION}

This study was done to create a new corpus which can be used in the linguistic field and show how people express their praises and which adjectives and adverbs they use to demonstrate satisfaction. As this topic was unique, the researcher could not find any study which was conducted before but there were lots of studies which were done in the field of corpus-based approach or study. Coxhead (2011) formed a new list for academic aims. Vongpumivitch, Huang, and Chang (2009) also
Table 2. The frequency of verbs and collocation of these verbs

\begin{tabular}{|c|c|c|}
\hline Frequency & Verb & Collocation \\
\hline 574 & Like & to see, brand, phone, most \\
\hline 542 & Use & this, these, watch \\
\hline 520 & Love & how, new, my, it \\
\hline 519 & Get & \\
\hline 508 & Do & \\
\hline 496 & Purchase & this, of \\
\hline 485 & Work & well, perfect, \\
\hline 475 & Make & \\
\hline 450 & Look & better, at, like \\
\hline 448 & Want & to use, it \\
\hline 446 & Fit & comfort, good, fine \\
\hline 443 & Think & \\
\hline 442 & Buy & this, these, them \\
\hline 442 & See & \\
\hline 394 & Know & \\
\hline 392 & Call & \\
\hline 391 & Put & \\
\hline 391 & Design & \\
\hline 391 & Find & myself \\
\hline 388 & Set & \\
\hline 385 & Display & piece, that \\
\hline 383 & Review & \\
\hline 382 & Come & \\
\hline 381 & Feel & \\
\hline 381 & Worth & wait, price, money \\
\hline 379 & Touch & \\
\hline 378 & Change & \\
\hline 378 & Clear & \\
\hline
\end{tabular}

searched the same topic with Coxhead (2011) while Wang, Liang and Ge (2008) discussed corpus for medical aims. Except for this examination of the word lists, Baayen and Lieber (1991) focused on morphology by searching productivity. They studied on affix in a corpus and tried to find out empirical data from English derivational morphology but Bolton, Nelson, and Hung (2002) concentrated on connectors in the writings of students. They wanted to find which connectors were overused or misused. Wold and Gibson (2005) discussed discourse coherence. By investigating discourse structure relations and they tried to create criteria for the convenient data structure. As a technological study, the study which was conducted on Twitter can be thought of as a leading study (Mowery, Smith, Cheney, Stoddard, Coppersmith, Bryan \& Conway, 2017). The researchers worked with depression-related Twitter data to describe the most common depressive symptom. On the other side, studying online review or a website is a very new topic. As technological devices have just spread all over the world, 
there is not enough study which was conducted in the field of online websites. Mudambi and Schuff (2010) can be thought of like pioneers in this field. Mudambi and Schuff (2010) led to a study on online websites so; this study can be considered as an inspiring study. They searched online consumer reviews on Amazon.com. They investigated factors what makes customer reviews helpful while consumer buying a product online but my study focused on reviews to be able to create a new corpus for online writing. While they addressed which factors are important for the consumer during the buying process, my study tried to find out which adjectives, adverbs, and verbs consumers use mostly while expressing their praises. Mudambi and Schuff (2010) found out that review extremity, review depth, and product type affect the helpfulness of the review. Especially review depth affects the helpfulness of the review positively. This result is in accordance with Piller's study (1999) and Zhu and Zhang's study (2006). Chen (2008), Chevalier and Mayzlin (2006), Clemons (2006), Ghose and Ipeirotis (2006) also have the same idea and think that reviews that are considered as helpful to customers have better potential value to companies, including increased sales. We also found that adjectives which show satisfactions are used mostly because people firstly check whether that product worthy of buying or not.

\section{CONCLUSION}

This study supports corpus-based studies. As technology is getting more and more popular, online corpus-based studies will be inevitable in the future so, the researcher purposes to provide a new corpus which investigates their tendency to express their own positive views through comments on Amazon.com. A new corpus type will be involved in corpus-based studies. To be able to create this corpus, the researcher tried to find frequently used adjectives, adverbs, and verbs which were collected by searching positive reviews on Amazon.com. The words used with them were also investigated. Our findings help linguists to create a new corpus for online reviewing. Particularly, linguists will easily focus on consumer reviews on websites thanks to this study since this study provides new ideas on corpus-based studies. Our analysis of positive consumer reviews points out that linguists can identify the tendency of consumers while choosing words in an online context. Thus, linguists can add new words to the corpus that were created at this study and develop the idea of the online corpus.

On the other side, this study will help educators to make a decision. As making a decision about which words or collocation of that word should be taught is difficult, this corpus-based study will give them new ideas and help educators while creating the syllabus. Teachers will be the weight off their shoulders because they can see mostly used words and will decide essential words and their collocations and adjust their programs according to this corpus. Thus, these words can be taught in classes for linguistic aims. Students can be acquainted with these words and keep up with the times.

This study has also an implication for practitioner writing skills. Until today, lots of genre types have been studied and discussed for writing. Most of them have still being used by teachers but as student profile change and digital technological devices have become popular, technology and writing online can be seen as a new genre type. That's why writing online review can be thought of as a new writing genre type. With the help of this corpus-based study, skill teachers will have already a list to teach which vocabularies should be used while writing the online review but the organization of this new genre type should be investigated by researchers. The content of this new genre type also should be addressed by future studies.

The researcher also tried to discover the tendency of consumers' word choice linguistically. The researcher tried to show how people can understand the context of online reviews. Previous research has shown that the mere presence of customer reviews on a website can improve customer perception of the website (Kumar \& Benbasat 2006). The researcher examined comments on Amazon.com and it was seen that comments have a significant role in their selling policies. The researcher also found that consumers generally use specific adverbs, adjectives, and verbs to express their sincerities. These words are effective ways to show truthfulness in reviews. As people don't have a chance to check if the product is good or bad, they want to rely on reviews and they are careful about adverbs, adjectives, and verbs. These words affect people ideas and selling rates in a hidden way. Especially adverbs have a profound effect on people's ideas. Amazon.com draw out customer reviews for several reasons, such as to serve as a mechanism to increase site "stickiness," and to bring in information about the product that can be sold to other online sellers (Mudambi \&Schuff, 2010). As online websites are getting more and more common in the modern world, every part of online selling is important. Customer reviews are one of the most significant parts of this business. It is so important to recognize what consumers write, how they express their ideas, which adjectives and adverbs are used. It is also pointed out that collocation words have an effect on reviews. In light of this information, understanding the effects of reviews will show us new paths to create a new corpus-based study area.

\section{Pedagogical Implications}

This study creates new ways of examining online reviews. With the help of my study, it is easily understood which adjective, adverb, and verb are used in a specific context. This information can easily adapt to a new corpus in the field of linguistic. This can be an inspiring corpus-based study for linguists. Writing an online review, answering to online reviews can be considered as different topics of writing classes. It is certain that students use technology in every part of their lives. Since technology and online shopping is the trend nowadays and we need to integrate daily life topics to education, writing review of a product can be a good topic for digital native. Since the importance of technology is known by most of the students, creating a new corpus for online writings will be a new idea in the field of education. This will broaden new horizons.

\section{REFERENCES}

Avery, C., Resnick, P., \& Zeckhauser, R. (1999). The market for evaluations. American Economic Review, 89(3), 564-584. 
Baayen, H., \& Lieber, R. (1991). Productivity and English derivation: a corpus-based study. Linguistics, 29(5), 801-844.

Ba, S. \& Pavlou, P. A. (2002). Evidence of the effect of trust building technology in electronic markets: Price premiums and buyer behavior. MIS quarterly, 243-268.

Bolton, K., Nelson, G., \& Hung, J. (2002). A corpus-based study of connectors in student writing: Research from the International Corpus of English in Hong Kong (ICEHK). International Journal of Corpus Linguistics, 7(2), 165-182.

Chen, P. (2008). “All Reviews Are Not Created Equal: The Disaggregate Impact of Reviews on Sales on Amazon. com," working paper, Carnegie Mellon University retrieved from http://ssrn.com/abstract=918083).

Chevalier, J. A., \& Mayzlin, D. (2006). The effect of word of mouth on sales: Online book reviews. Journal of marketing research, 43(3), 345-354.

Clemons, E. (2006). When online reviews meet hyperdifferentiation: A study of the craft beer industry. Journal of management information systems, 23(2), 149-171.

Coombs, W. T., \& Holladay, S. J. (2002). Helping crisis managers protect reputational assets: Initial tests of the situational crisis communication theory. Management Communication Quarterly, 16(2), 165-186.

Corson, D. (1997). The learning and use of academic English words. Language learning, 47(4), 671-718.

Coxhead, A. (2011). The Academic Word List 10 years on: Research and teaching implications. Tesol Quarter$l y, 45(2), 355-362$.

Dellarocas, C. (2007). Strategic manipulation of internet opinion forums: Implications for consumers and firms. Management science, 52(10), 1577-1593.

Ghose, A., and Ipeirotis, P. 2006. "Designing Ranking Systems for Consumer Reviews: The Impact of Review Subjectivity on Product Sales and Review Quality," in Proceedings of the $16^{\text {th }}$ Annual Workshop on Information Technology and Systems retrieved from http://pages.stern.nyu.edu/ panos/publications/wits2006.pdf

Godes, D., \& Mayzlin, D. (2004). Using online conversations to study word-of-mouth communication. Marketing science, 23(4), 545-560.

Harris, J., \& Gupta, P. (2008). 'You should buy this one!'The influence of online recommendations on product attitudes and choice confidence. International Journal of Electronic Marketing and Retailing, 2(2), 176-189.

Lee, J., Park, D. H., \& Han, I. (2007). The effect of negative online consumer reviews on product attitude: An information processing view. Electronic commerce research and applications, 7(3), 341-352.

Li, Y., \& Qian, D. D. (2010). Profiling the Academic Word List (AWL) in a financial corpus. System, 38(3), 402-411.

Kerkhof, P., \& van Noort, G. (2010). Third party internet seals: reviewing the effects on online consumer trust. In Encyclopedia of e-business development and management in the global economy (pp. 701-708). IGI Global.

Kumar, N., \& Benbasat, I. (2006). Research note: the influence of recommendations and consumer reviews on evaluations of websites. Information Systems Research, 17(4), 425-439.

Martínez, I. A., Beck, S. C., \& Panza, C. B. (2009). Academic vocabulary in agriculture research articles: A corpus-based study. English for specific purposes, 28(3), 183-198

Mowery, D., Smith, H., Cheney, T., Stoddard, G., Coppersmith, G., Bryan, C., \& Conway, M. (2017). Understanding depressive symptoms and psychosocial stressors on Twitter: a corpus-based study. Journal of medical Internet research, 19(2).

Mudambi, S. M., \& Schuff, D. (2010). Research note: What makes a helpful online review? A study of customer reviews on Amazon. com. MIS quarterly, 185-200.

Nation, I. S. (2001). Learning vocabulary in another language. Ernst Klett Sprachen.

Park, C., \& Lee, T. M. (2009). Information direction, website reputation and eWOM effect: A moderating role of product type. Journal of Business research, 62(1), 61-67.

Park, D. H., \& Kim, S. (2008). The effects of consumer knowledge on message processing of electronic wordof-mouth via online consumer reviews. Electronic Commerce Research and Applications, 7(4), 399-410.

Pavlou, P. A., \& Gefen, D. (2004). Building effective online marketplaces with institution-based trust. Information systems research, 15(1), 37-59.Piller, C. 1999. Everyone is a critic in cyberspace. Los Angeles Times (December 3).

Utz, S., Kerkhof, P., \& Van Den Bos, J. (2012). Consumers rule: How consumer reviews influence perceived trustworthiness of online stores. Electronic Commerce Research and Applications, 11(1), 49-58.

Kerkhof \& Utz, S. (2009). 'Egoboo’vs. altruism: the role of reputation in online consumer communities. New Media \& Society, 11(3), 357-374.

Valipouri, L., \& Nassaji, H. (2013). A corpus-based study of academic vocabulary in chemistry research articles. Journal of English for Academic Purposes, 12(4), 248-263.

Vongpumivitch, V., Huang, J. Y., \& Chang, Y. C. (2009). Frequency analysis of the words in the Academic Word List (AWL) and non-AWL content words in applied linguistics research papers. English for Specific Purposes, 28(1), 33-41.

Wang, J., Liang, S. L., \& Ge, G. C. (2008). Establishment of a medical academic word list. English for Specific Purposes, 27(4), 442-458.

Ward, J. (2009). A basic engineering English word list for less proficient foundation engineering undergraduates. English for Specific Purposes, 28(3), 170-182.

Whyte Jr, W. H. (1954). The web of word of mouth. Fortune, 50(5), 140-143.

Wolf, F., \& Gibson, E. (2005). Representing discourse coherence: A corpus-based study. Computational Linguistics, 31(2), 249-287.

Zhu, F., \& Zhang, X. (2006). The influence of online consumer reviews on the demand for experience goods: The case of video games. ICIS 2006 Proceedings, 25. 